\title{
Differential susceptibility of Morettini pears to blue mold caused by Penicillium expansum
}

\author{
Claudia V. Sánchez ${ }^{1,2 *}$, Carmo Serrano', M. Conceição Oliveira ${ }^{3}$, Paula Vasilenko", Mário Santos", \\ Rui M. Sousa ${ }^{1}$ \\ ${ }^{1}$ INIAV I.P., Instituto Nacional de Investigação Agrária e Veterinária, Quinta do Marquês, Oeiras, Portugal, ${ }^{2}$ GeoBioTec, Faculdade de Ciências \\ e Tecnologia, Universidade Nova de Lisboa, Caparica, Portugal, ${ }^{3}$ Centro Química Estrutural, Instituto Superior Técnico, Universidade de \\ Lisboa, Lisboa, Portugal
}

\section{A B S T R A C T}

Pear fruit (Pyrus communis L. cv Beurré Precoce Morettini) developing on the outside of canopy and exposed to sunlight acquires a bright redness on the exposed side, compared to the green peel fruit that develop within the canopy. At harvest, the main physicochemical parameters of the red and green side of the fruit, including firmness, brix and titratable acidity, were similar in pears harvested at the same day and stage of maturity. However, it was observed that fruits with a red side or that mostly green showed a different response to biotic stress, namely to pathogenic fungi attack. Actually, after 7 days under shelf-life conditions, red fruits demonstrated to be more resistant than green ones when challenged with a postharvest Penicillium expansum inoculation. Significant differences were observed in antioxidant activity and total phenolic compounds between both sides of the fruits. Several polyphenols related to mechanisms of induced resistance against fungal plant pathogens were identified in the extracts, such as catechin, quercetin, quinic acid or caffeoylquinic acid. These results suggest that the accumulation of phenolic compounds triggered by sun exposure may be one of the mechanisms responsible for the increased resistance of red-skinned Morettini pears.

Keywords: Antimicrobial properties; Antioxidant activity; Pathogenic fungi; Phenolic compounds; Fungal diseases

\section{INTRODUCTION}

'Beurré Precoce Morettini' pear is an Italian variety originated from the cross between 'Coscia x Williams' pears. The tree is vigorous in growth and fruits early and abundantly. Pears are harvested during the $3^{\text {rd }}$ week of July and can be stored under refrigeration during a maximum period of 1- 2 months. Fruits are middle large, pyriform and have a very good quality. They have a juicy, crunchy and sweet white pulp with a sweet-spicy flavor. Fruit skin is thin, semi-hard and smooth, with a basic green-yellow coloration that can develop a bright redness on the side exposed to the sunlight.

This cultivar is susceptible to pests like psylla and scab, and extremely susceptible to bacterial diseases like fire blight (Erwinia amylovora) and blossom blast (Pseudomonas syringae pv. syringae). In the field, an interesting characteristic was observed; pears with a red side or that mostly green show a different response to biotic stress, namely to pathogenic fungi attack. The green side of the fruit seems to be more susceptible to fungal infections.

Host plant resistance against fungal pathogens involves multiple defense mechanisms that can be included into several categories such as physiological factors and passive or active defense responses (Lattanzio et al., 2006). Fruit physiological factors such as firmness, $\mathrm{pH}$, sugar content and epicuticular waxes can affect the development of fungal pathogens (Alkan and Fortes, 2015).

Preformed phenolic compounds, like resorcinols or flavonoids may be particularly important in antifungal resistance. Moreover, active defense responses including induced antimicrobial compounds, defense-related proteins and reactive oxygen species may also be a key point in the fruit resistance against pathogens (Prusky and Keen, 1993; van Loon et al., 2006).

\footnotetext{
${ }^{*}$ Corresponding author:

Claudia V. Sánchez, INIAV I.P., Instituto Nacional de Investigação Agrária e Veterinária, Quinta do Marquês, 2784-505 Oeiras, Portugal Phone: 00351214403500, E-mail: claudia.sanchez@iniav.pt
} 
This study aimed to explain the differences in the susceptibility/resistance to fungal infection observed in Morettini pears from the same orchard and at the same stage of maturity.

\section{MATERIALS AND METHODS}

\section{Fruits}

Beurré Precoce Morettini pears (Pyrus communis L.) grown in an orchard located in Alcobaça (west region of Portugal) were hand-harvested at the stage of commercial maturity and stored in a cold room at $1^{\circ} \mathrm{C}$ and $90-95 \%$ RH until use.

For all the assays described throughout this work, pears were divided in 2 groups, in one group only the reddish part of the fruit was considered and in the other group only the greenish yellow part, hereafter called red and green, respectively.

\section{Pathogen}

The fungal pathogen Penicillium expansum was obtained from infected Rocha pears and maintained on potato dextrose agar (PDA). The pathogen was incubated at $25^{\circ} \mathrm{C}$ for 7 days. Spore suspensions were prepared as described in Janisiewicz and Marchi, 1992.

\section{Infection assays}

Fruits were surface-disinfected with $0.5 \%$ sodium hypochlorite and artificially wounded twice (each wound $15 \mathrm{~mm}$ apart from the equator of the fruit and to a depth and a diameter of $4 \mathrm{~mm}$ ), in the red or in the green part. The wounds were inoculated with $20 \mu \mathrm{L}$ of an aqueous suspension of $P$. expansum $\left(10^{4}\right.$ and $10^{3}$ conidia $\left./ \mathrm{mL}\right)$. The infected fruits were placed in boxes and incubated at $20-22^{\circ} \mathrm{C}$ (shelf-life conditions) during 7 days. The number of infected wounds and the diameter of the wounds were measured daily.

\section{Skin colour}

The colour of the fruit was determined with a Minolta chromameter (model CR-300, Data Processor 301, Minolta, USA). Three measurements were evaluated from each side of the fruits (red and green). The colour values were expressed by the CIELAB colorimetric system. The $\mathrm{L}^{*}$ value was used as an indicator of brightness. The values $\mathrm{a}^{*}$ and $\mathrm{b}^{*}$ were used to determine hue angle $\left(\mathrm{Hue}^{\circ}=\operatorname{arc} \tan \right.$ $\left.\mathrm{b}^{*} / \mathrm{a}^{*}\right)$. Hue values refers to a color wheel, with red-purple at an angle of $0^{\circ}$, yellow at $90^{\circ}$, bluish-green at $180^{\circ}$ and blue at $270^{\circ}$ (Mcguire, 1992).

\section{Firmness}

Firmness was measured by puncture, after skin removal, with a penetrometer (Penefel) fitted with an $8 \mathrm{~mm}$ diameter plunger. The firmness was expressed in $\mathrm{kgf} \mathrm{cm}^{-2}$.

\section{Titratable acidity and total soluble solids}

Pear samples were mashed and $20 \mathrm{~mL}$ of the pulp obtained was homogenized with $20 \mathrm{~mL}$ of distilled water. The homogenate was filtered and then titrated with 0.10 $\mathrm{N} \mathrm{NaOH}$ to $\mathrm{pH}$ 8.2. The volume of $\mathrm{NaOH}$ added was used to calculate the titratable acidity (TA), applying a multiplication factor of 0.67 . The results were expressed as $\mathrm{g}$ malic acid $\mathrm{L}^{-1}$ of juice.

The total soluble solids (TSS) content was determined by using a hand-held refractometer (Atago ATC-1E) at $20^{\circ} \mathrm{C}$. The results were expressed in ${ }^{\circ} \mathrm{Brix}$ (AOAC 2000).

\section{Extract preparation}

Extracts of pear were prepared following the method proposed by Swain and Hillis (1959). Briefly, $1 \mathrm{~g}$ of frozen sample (pulp and peel) was mixed with $5 \mathrm{~mL}$ of pure methanol (Merck), homogenized (Ultra-turrax apparatus) for $2 \mathrm{~min}$ and stored in darkness at $5^{\circ} \mathrm{C}$ for $24 \mathrm{~h}$. Afterward, samples were centrifuged at $12000 \mathrm{~g}$ at $10^{\circ} \mathrm{C}$ for $5 \mathrm{~min}$. The initial supernatants were separated and the pellets were rinsed once with the extraction solution. The extracts were then concentrated under vacuum $\left(30^{\circ} \mathrm{C}\right)$ until dryness. The residue was recuperated with purified water until a total volume of $1 \mathrm{~mL}$. All experiments were carried out in triplicate.

These extracts were used for the determination of both antioxidant activity and phenolic content.

\section{Total phenolic content and antioxidant activity}

Phenolic compounds were determined according to Vieira et al. (2009) with minor modifications. The extract $(0.25 \mathrm{~mL})$ was mixed with deionised water $(2 \mathrm{~mL})$ and $0.25 \mathrm{~mL}$ of Folin-Ciocalteu reagent. After $5 \mathrm{~min}, 5 \mathrm{~mL}$ of a sodium carbonate solution (20\%) plus $5 \mathrm{~mL}$ of distilled water were added and mixed well. One hour later, the absorbance was measured at $750 \mathrm{~nm}$ with an UV-VIS spectrophotometer (Shimadzu UV-160), using gallic acid (GA) as standard. The results were expressed as mg GAE $100 \mathrm{~g}^{-1} \mathrm{FW}$.

The antioxidant activity was determined by the DPPH method according to Shimada et al. (1992) with slight modifications. Extracts $(0.1 \mathrm{~mL})$ were mixed with $3.9 \mathrm{~mL}$ of a $0.05 \mathrm{mM}$ methanolic solution of DPPH (2,2-diphenyl-1-picrylhydrazyl radical) and shaken vigorously. The reaction mixture was allowed to stand for $30 \mathrm{~min}$ at room temperature in the dark. The absorbance of the mixture was determined at $517 \mathrm{~nm}$ using a UVVIS spectrophotometer (Shimadzu UV-160). Trolox and ascorbic acid were used as standards. The antioxidant activity of pear extracts was expressed as mg trolox $100 \mathrm{~g}^{-1}$ FW and mg AAE $100 \mathrm{~g}^{-1} \mathrm{FW}$. 


\section{HPLC-ESI-MS/MS analysis of phenolic compounds}

The identity of the phenolic compounds was confirmed by tandem mass spectrometry analysis. Two extracts were analyzed on an HPLC Dionex Ultimate 3000 composed of a binary pump HPG3200, an autosampler WPS300 and a column oven TCC3000 coupled in-line to a LCQ Fleet ion trap mass spectrometer equipped with an ESI ion source (Thermo Scientific). Aliquots of $10 \mu \mathrm{L}$ were injected into the column via a Rheodyne injector with a $25 \mu \mathrm{L}$ loop, in the partial injection mode. Separations were carried out with a Zorbax Eclipse Plus C18 (150 x 2.1 mm, $5 \mu \mathrm{m}$, Agilent Tecnologies) at $30^{\circ} \mathrm{C}$, using a mobile phase of $0.1 \%$ of acid formic in water ( $\mathrm{v} / \mathrm{v}$, eluent $\mathrm{A}$ ) and acetonitrile (eluent $\mathrm{B}$ ), and a gradient elution program of $0-2 \mathrm{~min}$ isocratic $5 \% \mathrm{~B}$, 2-20 min linear gradient to $40 \% \mathrm{~B}, 20-25$ min linear gradient to $90 \% \mathrm{~B}, 25-27 \mathrm{~min}$ isocratic $90 \% \mathrm{~B}$, and $27-30$ min linear gradient to $5 \% \mathrm{~B}$ (10 min reequilibration time). A flow rate of $0.8 \mathrm{mLmin}^{-1}$ was used, and the LC eluent was introduced into the ESI source in a post-column splitting ratio of 3:1.

The mass spectrometer was operated in the ESI positive and negative ion modes, with the following optimized parameters: ion spray voltage, $\pm 4.5 \mathrm{kV}$; capillary voltage, $16 /-18 \mathrm{~V}$; tube lens offset, $-70 / 58 \mathrm{~V}$, sheath gas $\left(\mathrm{N}_{2}\right)$, 80 arbitrary units; auxiliary gas $\left(\mathrm{N}_{2}\right), 5$ arbitrary units; capillary temperature, $270^{\circ} \mathrm{C}$. Spectra typically correspond to the average of $20-35$ scans, and were recorded in the range between 100-1000 Da. Tandem mass spectra $\left(\mathrm{MS}^{\mathrm{n}}, \mathrm{n}=2-3\right)$ were obtained with an isolation window of $2 \mathrm{~m} /$ z units, $20-30 \%$ relative collision energy and with an activation energy of $30 \mathrm{msec}$. Data acquisition and processing were performed using the software Xcalibur 2.2.

$\mathrm{MS}^{2}$ experiments were used to characterize both flavonoid aglycones and glycosides; whereas $\mathrm{MS}^{3}$ analysis was used in the fragmentation of flavonoid glycosides to their aglycones. The nomenclature for flavonoid aglycone fragmentations proposed by Claeys and co-workers were adopted to denote the various fragment ions (Vukics and Guttman, 2010).

\section{Statistical analysis}

All the results were submitted to analysis of variance (ANOVA). The mean values were compared by using Tukey test. The statistical significance was assessed at $p<0.05$.

\section{RESULTS AND DISCUSSION}

Morettini pears were harvested on the same day from the same orchard and divided in two groups according with the color of the skin. Fruits grown on the outside of the tree, more exposed to the sunlight, developed an attractive red blush during ripening $\left(\mathrm{Hue}^{\mathrm{O}}=62\right)$. Meanwhile, pears developed in the tree interior showed a greenish yellow skin, with a hue value of about 112 (Fig. 1a and Table 1). Significant differences in lightness were observed between both sides (Table 1).

In general, the physicochemical parameters of the red and green side of the fruit were similar, without significant differences in firmness, brix and titratable acidity (Table 1).

Aiming at confirming the differences observed in the field between red and green side in terms of incidence of rots, a controlled infection assay was performed. The pathogenic fungus $P$. expansum, one of the main responsible for postharvest decays in apples and pears, was chosen for the assay (Conway et al., 2004; Sánchez et al, 2012). Artificially wounded pears were inoculated with a suspension of $P$. expansum and incubated at room temperature. After $72 \mathrm{~h}$, all the wounds were colonized by $P$. expansum (disease incidence $=100 \%$ ); however the progress of the disease in the green side was clearly faster than in the red side of the fruit (Fig. 1b). Five days after inoculation, the size of the infected wounds remained significantly different $(p<0.05)$. The diameter of the lesions in the red part was about $8 \%$ and $11 \%$ smaller than in the green part, for pathogen concentrations of $10^{4}$ and $10^{3}$ conidia/mL, respectively (Fig. 2). After 7 days of incubation, the evolution of the lesions maintained the trend, with significant differences of about $5 \%$ and $9 \%$ (data not shown).

A similar behavior was previously observed in mango fruit. Fruits with a red coloration in their peel were more resistant than entirely green when challenged with a Colletotrichum gloeosporioides fungal inoculation. This increased resistance was linked to the accumulation of anthocyanin and flavonoids (Sivankalyani et al., 2015).

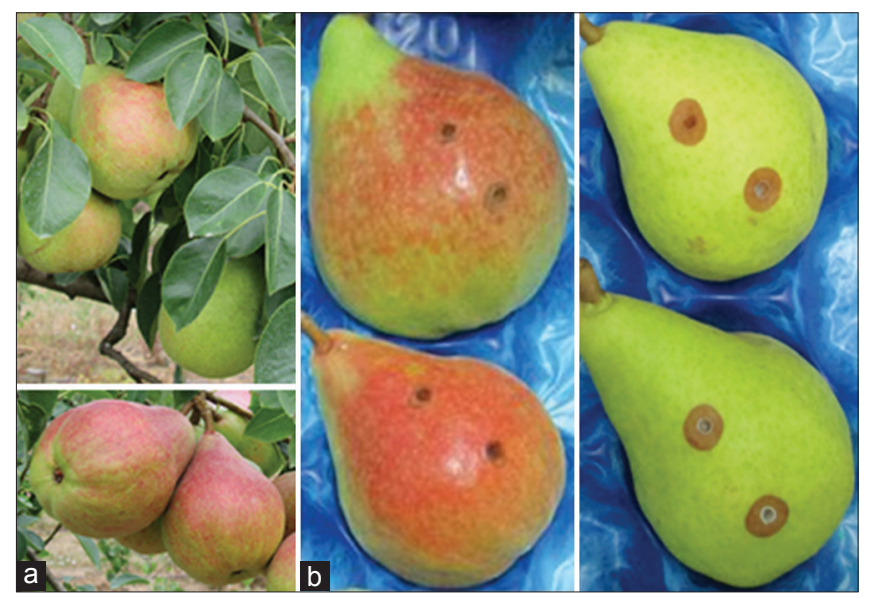

Fig 1. (a) Differences in skin coloration of Morettini pears related to sunlight exposure during ripening. (b) Aspect of the artificially wounded pears inoculated with $20 \mu \mathrm{L}$ of an aqueous suspension of $P$. expansum $\left(10^{3}\right.$ conidia $/ \mathrm{mL}$ ) after $72 \mathrm{~h}$ of incubation at $20-22^{\circ} \mathrm{C}$ (shelf-life conditions). 
Table 1: Physicochemical parameters of Morettini pears according to the fruit side analyzed: Lightness ( $\left.L^{*}\right)$, hue angle (Hue $)$, firmness, total soluble solids (TSS) and titratable acidity (TA)

\begin{tabular}{|c|c|c|c|c|c|}
\hline \multirow{2}{*}{$\begin{array}{l}\text { Fruit } \\
\text { side }\end{array}$} & \multicolumn{5}{|c|}{ Parameter } \\
\hline & $L^{*}$ & $\mathrm{Hue}^{\circ}$ & Firmness $\left(\mathrm{kgf} \mathrm{cm}^{-2}\right)$ & TSS (Brix) & TA (g malic acid $L^{-1}$ ) \\
\hline Red & $50.99 \pm 1.42^{a}$ & $61.98 \pm 5.08^{a}$ & $4.81 \pm 0.26^{a}$ & $12.80 \pm 0.35^{a}$ & $6.07 \pm 0.18^{a}$ \\
\hline Green & $68.08 \pm 0.13^{b}$ & $112.54 \pm 0.36^{b}$ & $4.96 \pm 0.23^{a}$ & $12.60 \pm 0.13^{\mathrm{a}}$ & $6.28 \pm 0.18^{a}$ \\
\hline
\end{tabular}

Values represented as mean \pm SD ( $n=18$ for $\mathrm{L}^{*}$, Hue angle and firmness, $n=9$ for TSS and $n=3$ for TA). Different letters within the same column indicate significant statistical differences $(p \leq 0.05)$

Table 2: Total phenolic content and antioxidant activity of methanolic extracts of Morettini pears

\begin{tabular}{|c|c|c|c|}
\hline \multirow{2}{*}{$\begin{array}{l}\text { Fruit } \\
\text { side }\end{array}$} & \multirow{2}{*}{$\begin{array}{c}\text { Total phenols } \\
\text { (mg GAE } \\
\left.100 \mathrm{~g}^{-1} \mathrm{FW}\right)\end{array}$} & \multicolumn{2}{|c|}{ Antioxidant activity } \\
\hline & & $\begin{array}{l}\text { (mg trolox } \\
\left.100 \mathrm{~g}^{-1} \mathrm{FW}\right) \\
\end{array}$ & $\begin{array}{c}\text { (mg AAE } \\
\left.100 \mathrm{~g}^{-1} \mathrm{FW}\right)\end{array}$ \\
\hline Red & $336.59 \pm 16.42^{a}$ & $141.45 \pm 6.56^{a}$ & $77.12 \pm 3.58^{\mathrm{a}}$ \\
\hline Green & $214.97 \pm 16.02^{b}$ & $118.01 \pm 5.47^{b}$ & $60.28 \pm 2.80^{b}$ \\
\hline
\end{tabular}

All the values are means $\pm \operatorname{SD}(n=6)$. Values within a column followed by different letters are significantly different $(p \leq 0.05)$. GAE: Gallic acid equivalent, FW: Fresh weight, AAE: Ascorbic acid equivalent

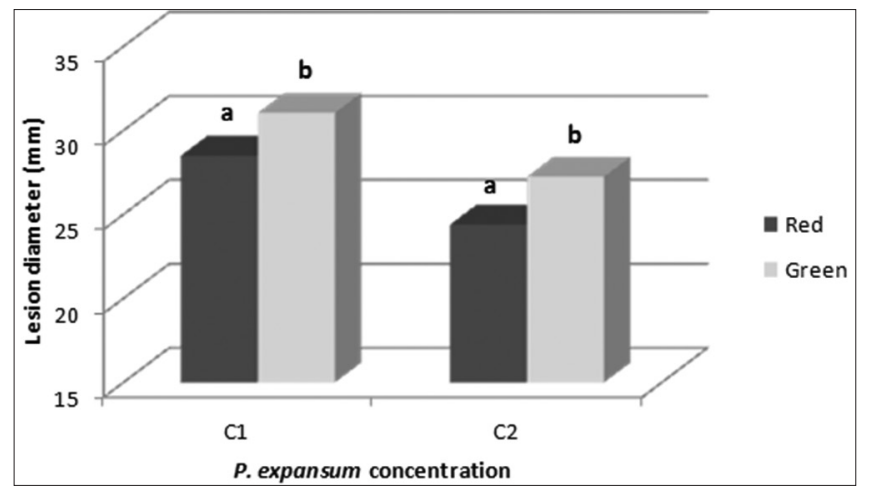

Fig 2. Diameter of the lesions caused by $P$. expansum inoculated into pear wounds, after 5 days of incubation at room temperature and $85 \%$ $\mathrm{RH}$ (shelf-life conditions). Data shown are the means for replicates of 18 wounds each. C1, $10^{4}$ conidia $/ \mathrm{mL} ; \mathrm{C} 2,10^{3}$ conidia $/ \mathrm{mL}$. Different letters indicate significant differences $(p \leq 0.05)$ between red and green side, for each pathogen concentration used.

It is well described that plants exposed to ambient sunlight protect themselves from the harmful ultraviolet- $B$ radiation by adjusting their antioxidant systems, as well as by synthesizing phenolic compounds, which act as a protective screen inside the epidermis (Carletti et al., 2003).

In the other hand, there is already evidence that the accumulation of phenolic compounds in the tissues is one of the mechanisms developed by plants against fungal pathogens. Plants react to diverse phytopathogens by using constitutive or induced phenolic substances, affecting the susceptibility or resistance characteristics of the plant (Beckman, 2000).

Therefore, in Morettini pears the accumulation of phenolic compounds in the red side as response to sunlight exposure could be one of the causes for the higher resistance to fungal infection when comparing with the green side. Total soluble phenolic compound content in pear extracts was measured by the Folin-Ciocalteau method. Results showed a high concentration of phenolic compounds in both types of samples, however in the red side the accumulation was significantly higher $(\geq 50 \%)$ than in the green part of the fruit (Table 2).

In general, the phenolic concentration measured in both samples was in the order of magnitudes reported for fruits considered at an intermediate level of phenolic content, like apple (211-347 mg GAE $100 \mathrm{~g}^{-1}$ ), banana (52-231 mg GAE $\left.100 \mathrm{~g}^{-1}\right)$, grape (145-196 mg GAE $\left.100 \mathrm{~g}^{-1}\right)$, orange (31-337 mg GAE $\left.100 \mathrm{~g}^{-1}\right)$, pineapple (47-174 mg GAE $\left.100 \mathrm{~g}^{-1}\right)$, apricot (133-178 mg GAE $\left.100 \mathrm{~g}^{-1}\right)$ and guava (170-345 mg GAE $\left.100 \mathrm{~g}^{-1}\right)$. Specifically, for pears, the values reported in literature are around $40-220 \mathrm{mg}$ GAE $100 \mathrm{~g}^{-1}$ (Brat et al., 2006; Wu et al., 2004).

When compared with other pear cultivars like D'Anjou, Packams, Abate, General Leclerc, Passe Crassane and Rocha, Morettini pears presented the highest concentration of phenolic compounds, mainly in red fruits (Salta et al., 2010; Galvis Sánchez et al., 2003).

It is well established that polyphenols have strong antioxidant activities and there is a significant correlation between phenolic concentration and free radical scavenging activity (Triantis et al., 2005). The antioxidant activity of the extracts was determined by the DPPH radical scavenging method. The differences observed in the content of total antioxidant compounds agreed with the results previously observed for the phenolic contents. The antioxidant activity measured in the extracts of the red part was approximately $20-28 \%$ higher than in the green one (Table 2).

In a first approach to analyze the phenolic compounds present in the samples of Morettini pears, the HPLC-PDA analysis of the extracts showed identical phenolic profiles, yielding phenolic acids, catechins and flavonoids (data not shown). However, the proportion of each compound differed in the two types of analyzed samples (red or green part of the fruit). These results allow explaining the differences in the antioxidant activities found in the fruit extracts analyzed (Table 2). On the other hand, neither the red nor the green part of the fruit contained anthocyanins (data not shown). 
Identification and peak assignment of individual polyphenols was carried out by HPLC-ESI-MS/MS based on comparison of their retention times, MS spectra and fragmentation patterns with those of standards (rutin and quercetin-3-O-glucoside) or published data. The 12 compounds identified or tentatively identified are listed in Table 3, along with retention times, structures and mass spectrometric characterization for each compound.

The presence of catechin, rutin and quercetin is well described in Pyrus communis L. (Galvis Sánchez et al., 2003) and these compounds have been confirmed in the analyzed extracts (peak 4- catechin, $m / z$ 289; peak 5-rutin, $m / z 609 / 611$; and peak 6-quercetin-3-O-glucoside, $m / z 463 / 465$, Table 3). Moreover, the identification of several additional glycosides of quercetin and isorhamnetin is highlighted with two quercetin glycosides derivatives: quercetin-manonylhexoxide (peak $7, m / z, 549 / 551$ ) and quercetin-acetyl hexoside (peak $8, \mathrm{~m} / z 505$ ), and four compounds that involved isorhamnetin glycosides and derivatives, namely isorhamnetin-O-rhamnose-glucoside (peak 9, $m / z$ 625) isorhamnetin-3-O-glucoside (peak 10,

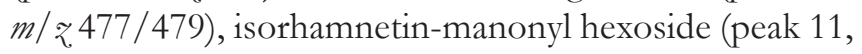
$m / z 563 / 565$ ), and isorhamnetin-acetyl hexoside (peak

Table 3: Identification by HPLC-ESI-MS/MS of the phenolic compounds present in methanolic extracts of Morettini pears

\begin{tabular}{|c|c|c|c|c|c|}
\hline Peak & Rt (min) & Structure & $\begin{array}{c}{[\mathrm{M}+\mathrm{H}]^{+} /[\mathrm{M}-\mathrm{H}]^{-}} \\
(\mathrm{m} / \mathrm{z})\end{array}$ & $\mathrm{MS}^{2}(\mathrm{~m} / \mathrm{z}, \%$, lon attribution) & Proposed compound \\
\hline 1 & 0.8 & & $-/ 191$ & $\begin{array}{l}\mathrm{MS}^{2}[191]: 173(10)[\mathrm{M}-\mathrm{H}-18]^{-} \\
129(15)[\mathrm{M}-\mathrm{H}-62]^{-}, 111(100)[\mathrm{M}-\mathrm{H}-62]^{-}\end{array}$ & Quinic acid \\
\hline 2 & 4.3 & & $-/ 353$ & $\begin{array}{l}\mathrm{MS}^{2}[353]: 191(90)[\mathrm{M}-\mathrm{H}-152]^{-} \\
179(100)[\mathrm{M}-\mathrm{H}-146]^{-}, 123(80)[\mathrm{M}-\mathrm{H}-202]^{-}\end{array}$ & Caffeoylquinic acid \\
\hline 3 & 5.3 & & $-/ 577$ & $\begin{array}{l}\mathrm{MS}^{2}[577]: 425(100)[\mathrm{M}-\mathrm{H}-152]^{-} \\
407 \text { (40) }[\mathrm{M}-\mathrm{H}-(152+18)]^{-} \\
289 \text { (25) }[\text { Cat-H] }\end{array}$ & Procyanidin dimer \\
\hline 4 & 5.9 & & $-/ 289$ & $\begin{array}{l}\mathrm{MS}^{2} \text { [289]: } 245(100)[\mathrm{M}-\mathrm{H}-44]^{-} \\
205 \text { (40) [M-H-84]-, } 179(20)[\mathrm{M}-\mathrm{H}-110]^{-}\end{array}$ & Catechin or epicatechin \\
\hline 5 & 8.6 & & $611 / 609$ & $\begin{array}{l}\mathrm{MS}^{2}[609]: 463(2)[\mathrm{M}-\mathrm{H}-162]^{-}\left(\mathrm{Y}_{1}-\right) \\
343(20)[\mathrm{M}-\mathrm{H}-162-120]^{-} \\
\left({ }^{0,2} \mathrm{X}_{0^{-}}\right), 301(100)[\mathrm{M}-\mathrm{H}-308]^{-}\left(\mathrm{Y}_{0^{-}}\right) \\
300(80)\left(\mathrm{Y}_{0^{-}} \mathrm{H}^{\circ}\right) \\
179(4)^{1,2} \mathrm{~A}^{-}\end{array}$ & Rutin \\
\hline 6 & 8.9 & & $465 / 463$ & $\begin{array}{l}\mathrm{MS}^{2}[463]: 301(100)[\mathrm{M}-\mathrm{H}-162]^{-}\left(\mathrm{Y}_{0}^{-}\right) \\
300(50)\left(\mathrm{Y}_{0}-\mathrm{H}^{*}\right) \\
179(7)^{1,2} \mathrm{~A}^{-}, 151(5)^{1,2} \mathrm{~A}^{-}-\mathrm{CO}\end{array}$ & Quercetin-3-O-glucoside \\
\hline 7 & 9.4 & & $551 / 549$ & $\begin{array}{l}\mathrm{MS}^{2}[549]: 505(100)[\mathrm{M}-\mathrm{H}-44] \\
\mathrm{MS}^{3}[505]: 463(45)[\mathrm{M}-\mathrm{H}-42]^{-} \\
301(100)[\mathrm{M}-\mathrm{H}-(162+42)]^{-}\left(\mathrm{Y}_{0}^{-}\right) \\
300(70)\left(\mathrm{Y}_{0}^{-} \mathrm{H}^{-}\right), 179(10)^{1,2} \mathrm{~A}^{-}, 151(4) \\
{ }_{1,2} \mathrm{~A}^{-}-\mathrm{CO}\end{array}$ & Quercetin- manonylhexoxide \\
\hline 8 & 9.6 & & $-/ 505$ & $\begin{array}{l}\mathrm{MS}^{2}[505]: 463(50)[\mathrm{M}-\mathrm{H}-42]^{-} \\
301(100)[\mathrm{M}-\mathrm{H}-(162+42)]^{-}\left(\mathrm{Y}_{0}^{-}\right) \\
300(90)\left(\mathrm{Y}_{0^{-}}-\mathrm{H}^{\circ}\right), 179(5)^{1,2} \mathrm{~A}_{-}, 151(4) \\
{ }_{1,2} \mathrm{~A}^{-}-\mathrm{CO}\end{array}$ & Quercetin-acetyl hexoside \\
\hline 9 & 9.8 & & $625 /-$ & $\begin{array}{l}\mathrm{MS}^{2}[625]: 479(50)[\mathrm{M}-\mathrm{H}-146]^{-} \\
317(100)[\mathrm{M}-\mathrm{H}-(162+146)]^{-}\left(\mathrm{Y}_{0^{-}}\right)\end{array}$ & Isorhamnetin-O-rhamnose-glucoside \\
\hline
\end{tabular}

(Contd)... 
Table 3: (Continued)

\begin{tabular}{|c|c|c|c|c|c|}
\hline Peak & Rt (min) & Structure & $\begin{array}{c}{[\mathrm{M}+\mathrm{H}]^{+} /[\mathrm{M}-\mathrm{H}]^{-}} \\
(\mathrm{m} / \mathrm{z})\end{array}$ & $\mathrm{MS}^{2}(\mathrm{~m} / \mathrm{z}, \%$, lon attribution) & Proposed compound \\
\hline 10 & 10.4 & & $479 / 477$ & $\begin{array}{l}\mathrm{MS}^{2}[477]: 357(10)[\mathrm{M}-\mathrm{H}-120]^{-} \\
315(40)[\mathrm{M}-\mathrm{H}-162]^{-}\left(\mathrm{Y}_{0}\right) \\
314(100)\left(\mathrm{Y}_{0}-\mathrm{H}^{\circ}\right), 285(20)\left(\mathrm{YO}^{-}-\mathrm{CH} 2 \mathrm{O}\right)\end{array}$ & Isorhamnetin-3-O-glucoside \\
\hline 11 & 11.3 & & $565 / 563$ & 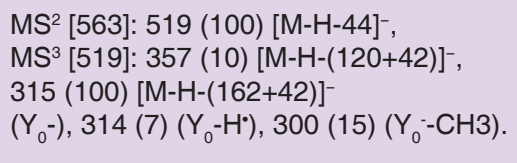 & Isorhamnetin-manonyl hexoside \\
\hline 12 & 11.4 & & $-/ 519$ & $\begin{array}{l}\mathrm{MS}^{2}[519]: 477(7)[\mathrm{M}-\mathrm{H}-42]^{-}, \\
357(10)[\mathrm{M}-\mathrm{H}-(120+42)]^{-}, \\
315(100)[\mathrm{M}-\mathrm{H}-(162+42)]^{-}\left(\mathrm{Y}_{0}-\right), \\
314(40)\left(\mathrm{Y}_{0}-\mathrm{H}^{*}\right), \\
300(15)\left(\mathrm{Y}_{0}^{-}-\mathrm{CH} 3\right), 285(8)\left(\mathrm{Y}_{0}^{-}-\mathrm{CH} 2 \mathrm{O}\right) .\end{array}$ & Isorhamnetin-acetyl hexoside \\
\hline
\end{tabular}

12, $\mathrm{m} / \mathrm{z}$ 519) (Schieber et al. 2002, Barros et al. 2013) (Table 3). Other phenolic compounds identified in the pear extracts are phenolic acids, namely quinic acid (peak $1, m / z 191$ ) and caffeoylquinic acid (peak 2, $m / z 353$ ); and one procyanidin dimer (peak 3, $\mathrm{m} / z$ 577) (Long-Ze and Harnyl, 2007).

Among the phenolic compounds identified, several of them have already been associated to disease resistance in fruits and vegetables (Lattanzio et al., 2006). For example, the first case confirmed was the increased resistance against smudge disease conferred by the accumulation of catechol and protocatechuic acid in onion scales (Walker and Stahmann, 1955). Phenolic compounds identified in olive plants like tyrosol, catechin, and oleuropein, have antifungal activity and protect plants against Phytophtora sp. (Del Río et al., 2003). Conidial germination of the fungus Neurospora crassa was completely inhibited by quercetin 3-methyl ether and its glucosides (Parvez et al., 2004). In citrus, phenolic compounds like quercetin, scopoletin and scoparone proved to be effective in reducing the severity and incidence of green mold disease caused by Penicillium digitatum (Sanzani et al., 2014).

Further studies are needed to investigate the accumulation patterns and the role of each one of the phenolic compounds identified in red and green Morettini pears.

\section{CONCLUSION}

The accumulation of phenolic compounds as consequence of a higher or longer exposition to sunlight is pointed out as one of the causes for the differential susceptibility or resistance of Morettini pears to fungal pathogens. The identification of phenolic compounds previously linked to fungal resistance supported these findings. Based on the results, it can be suggested that a late spring pruning, for example the removal of some branches from the interior of the tree 3-4 weeks before harvest to allow light penetration, could be a good agro-technical approach to increase the resistance to postharvest diseases in Morettini pear, increasing at the same time its nutritional value due to bioactive phenolic compounds accumulation.

\section{ACKNOWLEDGEMENTS}

The authors thank M.M. Ferreira-Pinto (ISA/UL) for P. expansum inoculum preparation. The HPLC-ESIMS/MS analysis has been financially supported by FCT - Fundação para a Ciência e Tecnologia (UID/ QUI/00100/2013 and REM2013).

\section{Authors' contributions}

C.V.S. was involved in the overall planning and supervision of the work, writing and paper review; M.S. and P.V. were mostly involved in experimental procedures; R.M.S. was responsible for the adaptation and production of Morettini pears; M.C.O. and C.S. performed the chromatographic analysis and contributed to writing the paper.

\section{REFERENCES}

Alkan, N. and A. M. Fortes. 2015. Insights into molecular and metabolic events associated with fruit response to postharvest fungal pathogens. Front. Plant Sci. 6. DOI: 10.3389/fpls.2015.00889.

AOAC. 2000. Official Methods of Analysis. $17^{\text {th }}$ ed. Association of Official Analytical Chemists, Washington, DC.

Barros, L., C. T. Alves, M. Duenas, S. Silva, R. Oliveira, A. M. Carvalho, M. Henriques, C. Santos-Buelga and I. C. F. Ferreira. 2013. Characterization of phenolic compounds in wild medicinal flowers from Portugal by HPLC-DAD-ESI/MS and evaluation of antifungal properties. Ind. Crops Prod. 44: 104-110.

Beckman, C. H. 2000. Phenolic-storing cells: Keys to programmed cell death and periderm formation in wilt diseases resistance and in general defense responses in plants. Physiol. Mol. Plant 
Pathol. 57: 101-110.

Brat, P., S. George, A. Bellamy, L. D. Chaffaut, A. Scalbert and L. Mennen. 2006. Daily polyphenol intake in France from fruit and vegetables. J. Nutr. 136: 2368-2373.

Carletti P, A. Masi, A. Wonisch, D. Grill, M. Tausz and M. Ferretti. 2003. Changes in antioxidant and pigment pool dimensions in UV-B irradiation maize seedlings. Environ. Exp. Bot. 50: 149-157.

Conway, W. S., B. Leverentz, W. J., Janisiewicz, A. B. Blodgett, R. A. Saftner and M. J. Camp. 2004. Integrating heat treatment, biocontrol and sodium bicarbonate to reduce postharvest decay of apple caused by Colletotrichum acutatum and Penicillium expansum. Postharvest Biol. Technol. 34: 11-20.

Del Río, J. A., A. G. Báidez, J. M. Botía and A. Ortuno. 2003. Enhancement of phenolic compounds in olive plants (Olea europaea L.) and their influence on resistance against Phytophthora sp. Food Chem. 83: 75-78.

Galvis Sánchez, A. C., A. Gil-Izquierdo and M. I. Gil. 2003. Comparative study of six pear cultivars in terms of their phenolic and vitamin C contents and antioxidant capacity. J. Sci. Food Agric. 83: 995-1003.

Janisiewicz, W. J. and A. Marchi. 1992. Control of storage rots on various pear cultivars with a saprophytic strain of Pseudomonas syringae. Plant Dis. 76: 555-560.

Lattanzio, V., V. M. T. Lattanzio and A. Cardinali. 2006. Role of phenolics in the resistance mechanisms of plants against fungal pathogens and insects. In: Filippo, I., editor. Phytochemistry: Advances in Research, Research Signpost, Kerala, India, Pp. 23-67.

Long-Ze, L. and J. M. Harnly. 2007. A screening method for the identification of glycosylated flavonoids and other phenolic compounds using a standard analytical approach for all plant materials. J. Agric. Food Chem. 55: 1084-1096.

Mcguire, R.G. 1992. Reporting of objective color measurements. HortScience. 27: 1254-1255.

Parvez, M. M., K. Tomita-Yokotani, Y. Fujii, T. Konishi and T. Iwashina. 2004. Effects of quercetin and its seven derivatives on the growth of Arabidopsis thaliana and Neurospora crassa. Biochem. Syst. Ecol. 32: 631-635.

Prusky, D. and N. Keen. 1993. Involvement of preformed antifungal compounds in the resistance of subtropical fruits to fungal decay. Plant Dis. 77: 114-119.

Sánchez, C., M. M. Ferreira-Pinto and M. G. Barreiro. 2012. Characterization of Aureobasidium pullulans, a promising biocontrol agent for postharvest diseases. Acta Hortic. 943: 335-342.

Salta, J., A. Martins, R. G. Santos, N. R. Neng, J. M. F. Nogueira, J. Justino and A. P. Rauter. 2010. Phenolic composition and antioxidant activity of Rocha pear and other pear cultivars - A comparative study. J. Funct. Foods. 2: 153-157.

Sanzani, S.M., L. Schena and A. Ippolito. 2014. Effectiveness of phenolic compounds against citrus green mould. Molecules. 19: 12500-12508.

Schieber, A., P. Keller, P. Streker, I. Klaiber and C. Reinhold. 2002. Extracts of apples (Malus domestica cv. "Brettacher") by HPLCPDA and HPLC-APCIMS/MS. Phytochem. Anal. 13: 87-94.

Shimada, K., K. Fujikawa, K. Yahara and T. Nakamura. 1992. Antioxidative properties of xanthone on the auto oxidation of soybean in cylcodextrin emulsion. J. Agric. Food Chem. 40(1992): 945-948.

Sivankalyani, V., O. Feygenberg, S. Diskin, B. Right and N. Alkan. 2015. Increased anthocyanin and flavonoids in mango fruit peel are associated with cold and pathogen resistance. Postharvest Bari. 2015. p. 86.

Swain, T. and W. E. Hillis. 1959. Phenolic constituents of Prunus domestica quantitative analysis of phenolic constituents. J. Sci. Food Agric. 10: 63-68.

Triantis, T., A. Stelakis, D. Dimotikali and K. Papadopoulos. 2005. Investigations on the antioxidant activity of fruit and vegetable aqueous extracts on superoxide radical anion using chemiluminescence techniques. Anal. Chim. Acta. 536: 101-105.

van Loon, L.C., M. Rep and C. M. Pieterse. 2006. Significance of inducible defense-related proteins in infected plants. Annu. Rev. Phytopathol. 44: 135-162.

Vieira, F., G. Borges, C. Copetti, L. Gonzaga, E. Nunes and R. Fett. 2009. Activity and contents of polyphenolic antioxidants in the whole fruit, flesh and peel of Three apple cultivars. Arch. Latino Am. Nutr. Órgan. Off. Soc. Latino Am. Nutr. 59(1): 101-106.

Vukics, V. and A. Guttman. 2010. Structural characterization of flavonoid glycosides by multi-stage mass spectrometry. Mass. Spectrom. Rev. 29: 1-16.

Walker, J. C. and M. A. Stahmann. 1955. Chemical nature of disease resistance in plants. Annu. Rev. Plant Physiol. 6: 351-366.

Wu, X., G. R. Beecher, J. M. Holden, D. B. Haytowitz, S. E. Gebhardt and R. L. Prior. 2004. Lipophilic and hydrophilic antioxidant capacities of common foods in the United States. J. Agric. Food Chem. 52: 4026-4037. 